\title{
Stocks return volatility clustering in Russian market:preconditions and interpretations
}

\author{
Nagapetyan R. Artur \\ Finance and Credit Department \\ Far East Federal University \\ Vladivostok, Russia \\ art9309@mail.ru
}

\begin{abstract}
Current article's research question is posed as follows: Are the dynamics of unilateral assets of coefficients' sensitivity to market changes and its asymmetry significant factors in the context of interpreting stocks return volatility based on the volatility clustering phenomenon? The authors develop the definition of clustering stocks return volatility according to the description of the interrelations among this phenomenon, Efficient Market Hypotheses and the existing pricing models of financial assets. The relative inability of the market to ensure full and coordinated implementation of accumulated information in asset price is a precondition for the emergence of the clustering of stocks return volatility at the micro-level. Directions for improving assessment of financial assets volatility are demonstrated, and approaches to arbitrage strategies formation for increasing the efficiency of market information are suggested.
\end{abstract}

Keywords-micro-level volatility clustering, Efficient Market Hypothesis, volatility forecasting, arbitrage, diversity

\section{INTRODUCTION}

Financial risks are the main objects in trade relations in the modern financial entrepreneurship market. It is important to develop the economy segment of appropriate emerging markets to stimulate investment attractiveness to attract investors both domestically and abroad. The market ability to express the aggregated effects of information flows in the dynamics of investment assets prices is a necessary condition for maintaining favorable investment climate.

A volatility clustering phenomenon in the prices dynamics of various financial instruments reflects the non-random nature of the observed volatility in different periods. This is an example of the element of market information inefficiencies. It also affects the business transactions costs magnitude in the economy on the whole. In this article, the authors consider various approaches to modeling the phenomenon of volatility clustering in different segments of the Russian financial market.

The Russian stock market is developing the financial macro institute with high indices of assets volatility. This fact also determines the relevance of this study. Return volatility of Russian market stocks is high. Theoretical constructions for interpreting the nature of the phenomenon of clustering stocks return volatility are not sufficiently developed. In modern conditions, investors should use dynamic approaches to the interpretation and forecasting of volatility and other financial instruments parameters. This is an important step to identify markets information inefficiency elements, to describe its relevant reasons and measures for reducing.

The relationship among the Efficient Market Hypothesis, the existing financial assets pricing models and the phenomenon of the clustering of stocks return volatility are important. Let us show that these relations exist and they can help to increase scientific knowledge in the field of full coordinated implementation of market information in describing the asset price processes. This, in turn, can become the basis for the formation of new financial instruments, institutions and regulatory norms to increase efficiency of information of emerging financial markets.

The volatility clustering phenomenon in time series, for example, the volatility clustering of financial assets return, was noted for the first time in the Mandelbrot's articles [1]. Later, Engle proposed an autoregressive conditional heteroscedasticity model, which became the basis for the emergence of a large number of models analyzing the volatility clustering phenomenon of predicting various risk and volatility indicators [2].

When analyzing these studies, the authors concluded that all of them are aimed at clarifying the approaches for volatility forecasting based on the volatility clustering phenomenon. It has great practical importance for risk management operations in conditions of cyclically unstable development of the world economy. However, these approaches usually do not provide an opportunity to answer the most important research questions. It is important to describe why markets have some volatility level and why the volatility dynamics has been changing in different periods in general. How does the volatility clustering phenomenon which underpin these processes correlate with the markets information efficiency theory and known models of equilibrium asset pricing? Is there a difference between clustering of stocks return volatility at the micro-level and return volatility clustering at the macrolevel? Which of these phenomena is primary? How is the mechanism of transformation arranged?

The research question of the urrent article is posed as follows: are the dynamics of coefficients of assets unilateral sensitivity to market changes and its asymmetry the significant 
factors in the context of interpretation of stocks return volatility based on the volatility clustering phenomenon?

\section{LITERATURE REVIEW}

In 1953, Kendall discovered and described the phenomena of connection of neighboring observations values during analysis of the volatility of financial and macroeconomic indicators [3]. Fig. 1 shows the Sberbank's ordinary stock daily return and conditional return volatility from 2012 to 2017.

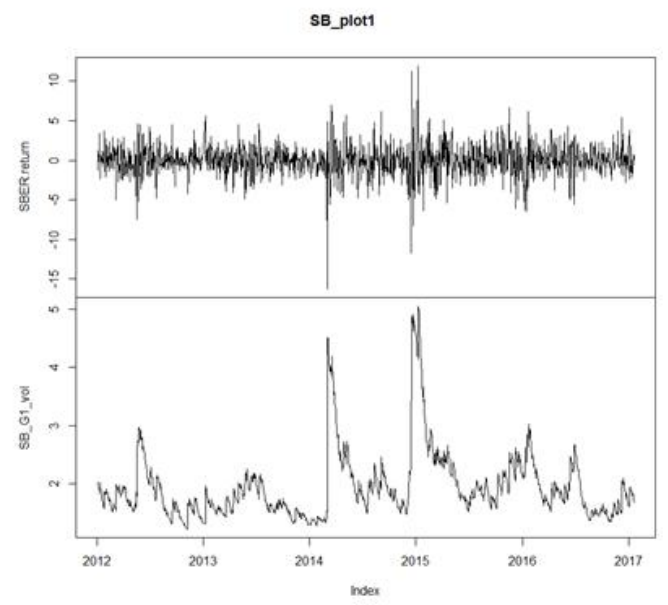

Fig. 1. Daily return of Sberbank's ordinary stock and conditional return volatility values from 2012 to 2017

One can see temporary clusters when the conditional stock return volatility values are high or low. This means that there is a connection between the neighboring values of daily conditional return volatility values. This relationship is the basis in most volatility forecasting models. After Markowitz's mean-variance analysis, this indicator has become an important characteristic of financial assets in risk management sphere [4].

Today's large price changes increase the likelihood of large price changes in the next period. This phenomenon was called volatility clustering by Mandelbrot [5]. Why is so much attention paid to this phenomenon? At first glance, it is not related to the essence of risk phenomena in the general case and, accordingly, volatility in this context. The fact is that the existence of the volatility clustering phenomenon has certain contradictions with Efficient Market Hypothesis [6]. If all existing asset information at a given moment in time is fully reflected in its price, then in the subsequent period, the price change and the characteristics of this change should depend only on the newly received information. If the neighboring volatility values are interrelated, this condition is violated.

Andreou considered the Efficient Market Hypothesis modeling approaches evolution under the influence of asset volatility concept transformation [7].

1. The Bachelier-Kendall period (1900-1960). Price fluctuations are random according to normal distribution (the first-generation random walk model). French mathematician
Louis Bachelier demonstrated that the dynamics of some commodities prices had a random character in stock exchange [8]. In 1934 -1937, there were many evidences that the stock's value dynamics is also random. Further, various researchers came to the conclusion that the predictions in the financial market were untenable. Even the analogies are given, which demonstrated that the stock's value dynamics could be compared with the drunk person movements who was trying to grab the surrounding objects [9].

2. The founder period of the fractals theory (1960-1980). Mandelbrot showed that the price fluctuations are random, but they do not obey the normal distribution (the secondgeneration random walk model - the martingale model). In 1962, Moore demonstrated in his article that there was a weak negative autocorrelation of separately considered assets return. However, this article demonstrated the insignificant positive autocorrelation in the dynamics of corresponding indices. It was revealed that the price dynamics of long-term asset could not not be described as a phenomenon of random walk properties in contrast to the short-term ones. In 1960, it was demonstrated that the use of averages data leads to identification of the data autocorrelation phenomenon, which is actually not available [10].

3. The dynamic volatility period $(1980$ - ...). The fluctuations are random, but each observation has its own distribution law, at least an individual volatility value (a thirdgeneration random walk model that takes into account the volatility clustering models based on conditional heteroscedasticity)

To understand the nature of the autoregressive conditional heterosecadality model (ARCH), it is necessary to consider the class of exponentially weighted moving average models (EWMA). An EWMA model is based on the assumption that future volatility values depend on the absolute value change of corresponding asset's price dynamics (1).

$$
\sigma_{t}^{2}=\lambda \sigma_{t-1}^{2}+(1-\lambda) u_{t-1}^{2}
$$

where, $\lambda$ is a constant which value is in the range from 0 to 1 and which characterizes the rate of the function decrease; $\sigma_{t}^{2}-$ the considered asset's volatility square is calculated by the results of period $\mathrm{t} ; u_{t-i}^{2}-$ the relative change square of the corresponding market indicator for previous period.

The EWMA model's advantage is possibility of using small databases for working with volatility forecast models. To predict the expected volatility in the next period, investors should know only two quantities, namely, the relative change square of the corresponding market indicator for the previous period. In that way, each new period, after receiving new values, the previous data can be deleted.

The exponential weighted average model makes it possible to interpret the volatility values dynamics. Coefficient $\lambda$ is important. It characterizes the relationship between the volatility values for different periods. If the value of $\lambda$ is close to zero, this means that future volatility values are highly dependent on the relative change square of the corresponding market indicator for the previous period. This also means that 
the volatility values will differ greatly from each other over different periods. If the value of $\lambda$ is close to one, this means that future volatility values will be similar to the volatility values in previous periods. This reduces the difference between the volatility values for different periods and allows ignoring the relative change square of the corresponding market indicator for the previous period. In this case, if an investor wants to know the value of volatility in the next period, he only needs to look at the value of volatility in the current period.

In 1982, for the first time, American econometrist Engle, the future Nobel laureate, proposed modeling the autoregressive conditional heteroscedasticity $(\mathrm{ARCH})$ model based on volatility. Initially, it was done to simulate inflation in the UK [2].

This model is a more complex version of the exponential weighted average model. Its internal mechanism describes similar interrelations. The future volatility values are determined on the long-term basis of value average variance. Also in the formula, there is the relative change square of the corresponding market indicator for some previous periods. The autoregressive conditional heteroscedasticity model can be represented in the following form (2).

$$
\sigma_{t}^{2}=\omega+\alpha_{1} u_{t-1}^{2}+\alpha_{2} u_{t-2}^{2}+\ldots+\alpha_{p} u_{t-m}^{2},
$$

where $\omega=\gamma V_{l}, V_{l}$ is a constant characterizing the value of the long-term variance; $\sigma_{t}^{2}$ is the considered asset's volatility square, calculated by the results of period $t ; u_{t-1}^{2}$ is the relative change square of the corresponding market indicator for previous periods.

The interpretation of $\alpha_{i}$ seems to be close to the interpretation of the $\lambda$ in the EWMA model. Accordingly, for large values coefficients $\alpha_{i}$, the expected volatility predicted values for future periods will strongly depend on the relative change square of the corresponding market indicator for previous periods. In addition, there will also be high asset's expected values volatility, considered for several periods. In the case of small considered coefficients values, the future volatility expected values estimates will, firstly, have low volatility, and secondly, they will be close to the value of long-term volatility. This model was further applied in order to simulate the volatility of almost all known types of financial assets, including stock prices and exchange rates [11].

In 1986, Bollerslev proposed the modification of the autoregressive conditional heteroscedasticity model in the form of the generalized autoregressive conditional heteroscedasticity model (GARCH) [12]. By its nature, it is even closer to the EWMA model, because, unlike ARCH, the new model takes into account the influence of the relative change square of the corresponding market indicator for previous periods and the considered asset's volatility square for the previous periods. Accordingly, the model GARCH (p, q) can be represented in the following form (3).

$\sigma_{t}^{2}=\omega+\alpha_{1} u_{t-1}^{2}+\ldots+\alpha_{p} u_{t-m}^{2}+\beta_{1} \sigma_{t-1}^{2}+\ldots+\beta_{q} \sigma_{t-n}^{2}$ where, $\omega=\gamma V_{l}, V_{l}$ is a constant characterizing the value of the long-term variance; $\sigma_{t}^{2}$ is the considered asset's volatility square, calculated by the results of period $t ; u_{t-1}^{2}$ is the corresponding market indicator relative change square for previous periods; $\sigma_{t-1}^{2}-$ the considered asset's volatility square for the previous periods.

All the coefficients' sum in the model must be equal to one (including . $\gamma$ ). Only in this case, the value of long-term volatility is positive.

The value of the long-term volatility can be found by dividing $\omega$ by $\gamma$. In this form, the model of generalized autoregressive conditional heteroscedasticity has become widespread. It is used to predict the assets return volatility. It is transformed to solve more specific problems [13, 14, 15].

Despite the GARCH $(1,1)$ prevalence, a large number of models of this class have been proposed. Some of them can give more accurate predictive values in special cases. Nelson described many examples of the number of models which take into account various asymmetric effects [16]. For example, it is known that in some market, positive and negative values $u_{i}$ influences the future volatility estimation in different ways. Often, negative shocks lead to a higher level of future volatility, which can be explained by higher investor's sensitivity to negative market' news. These are the GJRGARCH $\alpha+{ }_{\text {GR }}{ }^{\prime}$-GARCH-Glosten-Jagannathan-Runkle GARCH) models [17].

Another specification IGARCH (IGARCH - integrated GARCH) suggests that even during an infinite period of consideration of asset dynamics, the expected volatility values will depend, in part, on the initial conditions, which has a poor intuitive explanation [18].

The volatility growth should lead to expected return increasing, which also contradicts the pricing model of Capital assets (CAPM) [S\&R]. To solve this problem, a GARCH-M (GARCH-M-GARCH-in-mean) model was proposed. Exponential GARCH (EGARCH - exponential GARCH), includes the leverage effect. Quadratic GARCH (GQGARCH - generalized quadratic GARCH) and nonlinear GARCH (NGARCH - non-linear GARCH), which generalize the form of present and previous volatility values dependence, taking into account the small and large volatility values periods.

Hansen described a detailed analysis of GARCH models in the context of their predictive power. Morimune prepared another survey in this sphere [18].

Realized volatility models are class of models that allow predicting the financial assets volatility value. These models are also based on volatility clustering phenomenon using. The volatility values of time series of future periods depend on volatility in previous periods. It is necessary to have intraday high-frequency data to use this class of models.

The realized volatility calculation of intraday is based on the calculation of sum squares of asset intraday returns. There are many calculation modifications of this parameter, including approaches with the weighting of individual return observations, for example, based on the volume of trades [19]. 
One of the methods can be presented in the following form (4).

$$
\sigma_{t}^{2}=\sum_{n=1}^{N_{t}} r_{n, t}^{2}
$$

where, $\sigma_{t}^{2}$ is considered asset's volatility square, calculated by the results of period $\mathrm{t} ; r_{n, t^{-}}^{2}$ the square of the logarithmic return at the moment $\mathrm{n}$ of day $\mathrm{t} ; N_{t}$ - number of return observations within day $\mathrm{t}$.

This volatility calculating method is simple, but there are some difficulties. In this model, there is a microstructure noise. Analysis of some problems can be found in the next articles, published by Harris, Zhou and Andersen [20]. For example, there is an asymmetry in short-term period trading due to information asymmetry. There are also problems arising during analyzing foreign investments [21]. Arbitrage operations in some cases are possible, so conventional pricing models can not be used. The period is important for calculating intraday profitability. Hansen and Bundy proposed using the 20- and 15-minute period. Areal and Corsi demonstrated positive aspects of realized volatility calculating [22].

Corsi offered a method for predicting the magnitude of realized volatility - the Heterogeneous Autoregressive model of realized volatility (HAR-RV). There are three parameters in the model. The realized volatility values in the future period depends on the realized volatility values in the past period, as well as the realized volatility value during the previous week and month. Wang, Craioveanu and Ceylan developed this model in their articles. The Heterogeneous Auto-Regressive model of realized volatility can be represented as follows (5).

$$
\sigma_{\mathrm{t}+1 \mathrm{~d}}^{(\mathrm{d})}=\mathrm{c}+\beta^{(d)} \mathrm{RV}_{\mathrm{t}}^{(\mathrm{d})}+\beta^{(w)} \mathrm{RV}_{\mathrm{t}}^{(\mathrm{w})}+\beta^{(m)} \mathrm{RV}_{\mathrm{t}}^{(\mathrm{m})}+\varepsilon_{t}
$$

where $\sigma_{t+1 d}^{(d)}$ - is the volatility forecast estimate for one day, $\mathrm{RV}_{\mathrm{t}}^{(\mathrm{d})}$ - is the realized volatility estimate calculated using (4), $w=5, m=22, \mathrm{RV}_{\mathrm{t}}^{(n)}=\left(R V_{t}+\cdots+R V_{t-n+1}\right) / n, \varepsilon_{t}-$ is the model error that obeys the "white noise" law

In 2012, Liu prepared a survey describing most of the approaches of modeling realized volatility [23]. Liu suggests using five-minute intervals to calculate intraday profitability for assessing intraday realized volatility values.

\section{RESEARCH HYPHOTHESES}

\section{Hypothesis №1}

Dynamics of coefficients of assets unilateral sensitivity to market changes (show a market's assessment interval) is a significant factor in the context of stocks return volatility interpretation based on the volatility clustering phenomenon.

\section{Hypothesis №2}

There is an asymmetry in the dynamics of coefficients of assets unilateral sensitivity to market changes.

\section{Hypothesis №3}

Asymmetry in the dynamics of coefficients of assets unilateral sensitivity to market changes is a significant factor in the context of ${ }^{+}$inferp Yetation of stocks (return volatility based on the volatility clustering phenomenon.

\section{Hypothesis №4}

The equality of coefficients of assets unilateral sensitivity to positive and negative market changes is a necessary condition for the absence of arbitrage opportunities in the financial market.

\section{METHODOLOGY AND DATA}

There are two fundamental questions. This approach was first used by Taylor. How much money is an investor ready to pay to buy this asset? (Maximum purchase price) How much money does an investor require to sell this asset? (The minimum selling price) Each investor answers these two questions at any given time. Answers form an individual interval for the asset valuation for this investor. The more the investor is confident in his asset assessment, the less his individual interval. The market valuation interval is formed on the set basis of individual intervals.

The larger the current asset assessment market interval, the higher the measure of uncertainty assessment of the asset current value. It means that its price has high changing probability in the next period. Therefore, the larger the interval of the current asset assessment market, the higher the expected values of asset volatility in the next period. Let us propose evaluating the interval of the current asset assessment market by coefficients of assets unilateral sensitivity to market changes (show a market's assessment interval). This is the main idea of the authors' first hypothesis $\alpha+\beta=\chi$.

On the other hand, asymmetry in the dynamics of coefficients of assets unilateral sensitivity to market changes is possible. The authors believe that this asymmetry in the current period may also lead to a high volatility in the next period. The basic idea depends on the place, where exactly the current asset's price is located relative to the interval boundaries of the current asset assessment market. If it is in the middle of this interval, then there can be no asymmetry. Asymmetry can be if the current asset's price is closer to one of the edges of the interval of current asset assessment market. But this state is not stable. Market participants make arbitrage operations and bring the current price closer to the middle position of the market interval. This in turn leads to changing current price. The expected changing of the current price in the next period leads to increasing volatility. This is the main idea of the third authors' hypothesis.

The authors can find the current price location in relation to its market interval boundaries, using the asymmetry in the dynamics of coefficients of assets unilateral sensitivity to market changes. The deviation of the current price from the middle of the market interval is important. Accordingly, the second hypothesis asserts that there is an asymmetry in the dynamics of coefficients of assets unilateral sensitivity to market changes. 
The fourth hypothesis has a deeper meaning. A new class of arbitrage transactions can be proposed based on it. There are other practical suggestions too, which the authors will consider later.

Next, let us describe the plan of testing the hypotheses proposed in the article. First, it is necessary to show that there is volatility clustering phenomenon in the Russian stock market, using the generalized conditional autoregressive heteroscedasticity model - GARCH $(1,1)$ in the form $(6)$.

$$
\sigma_{t}^{2}=\omega+\alpha_{1} u_{t-1}^{2}+\beta_{1} \sigma_{t-1}^{2}
$$

Let us use 25 data of the most liquid stocks daily values in various sectors of the Russian market. Next, let us test hypothesis 2. Equation (7) helps to calculate the coefficients of assets unilateral sensitivity to market changes [24].

$$
E_{t}^{i}=\beta_{0}+\beta_{1}^{+} \delta^{+} E_{t}^{M}+\beta_{2}^{-} \delta^{-} E_{t}^{M}+u_{t}
$$

where, $\mathrm{E}_{\mathrm{t}}^{\mathrm{i}}$ and $\mathrm{E}_{\mathrm{t}}^{\mathrm{M}}$ are the asset and market index daily returns in period $\mathrm{t} ; \delta^{+}, \delta^{-}$- dummy variables showing various possible combinations of asset's price and market index changes; $\beta_{1}^{+}, \beta_{2}^{-}$- coefficients reflecting different assets sensitivity to market changes.

Second, hypothesis verification can be done by using Chow test, namely, the simultaneous equality $\beta_{1}^{+}, \beta_{2}^{-}$ parameters for each considered period should be checked. Then two variables are formed. To test both first and third hypotheses, regression (8) is evaluated. It demonstrates significance of $a_{1 t}$ and $a_{2 t}$ variables.

$$
\sigma_{t}^{2}=\omega_{0}+\omega_{1} \sigma_{t-1}^{2}+\omega_{2} a_{1 t}+\omega_{3} a_{2 t}+\varepsilon_{t}
$$

where, $\sigma_{t}^{2}$ is the realized volatility value in day t, $a_{1 t}=$ $\left(\beta_{1}^{+}+\beta_{2}^{-}\right)$is a variable reflecting Dynamics of coefficients of assets unilateral sensitivity to market changes; $a_{2 t}$ is a dummy variable that reflects asymmetry in the dynamics of coefficients of assets unilateral sensitivity to market changes, calculated by using Chow test and assuming 1, when there is asymmetry and 0 otherwise.

This time, let us use 5 minutes stocks return values for this sample. To obtain more justified results, factor $\sigma_{t-1}^{2}$ is added to the regression.

Equation (9) demonstrates the fourth hypothesis idea.

$$
\frac{\beta_{i}^{+}}{\beta_{i}^{-}}=\frac{\beta_{j}^{+}}{\beta_{j}^{-}}=1
$$

where, $\beta_{i}^{+}\left(\beta_{j}^{+}\right), \beta_{i}^{-}\left(\beta_{j}^{-}\right)$are coefficients reflecting different assets sensitivity to positive (negative) market changes.

All data were taken from Finam database. Calculation is made by using Stata and R.

\section{RESUlTS}

There are phenomena of clustering stocks return volatility in the Russian market. Calculating results of stock's conditional volatility by using Generalized conditional autoregressive Heteroscedasticity modelling for 25 most liquid

\begin{tabular}{|c|c|c|c|c|}
\hline $\begin{array}{ll}\text { Asset } & \\
& \alpha+\end{array}$ & $\beta=\chi_{l}$. & ${ }_{(1)} \boldsymbol{\gamma}$ & $\boldsymbol{\alpha}_{\mathbf{1}}$ & $\boldsymbol{\beta}_{1}$ \\
\hline ROSN & 1.4142 & 0.01 & 0.03 & 0.96 \\
\hline GAZP & 1.5275 & 0.03 & 0.04 & 0.93 \\
\hline $\mathrm{LKOH}$ & - & 0.00 & 0.07 & 0.93 \\
\hline NVTK & 1.8708 & 0.04 & 0.08 & 0.88 \\
\hline TRNFP & - & 0.00 & 0.09 & 0.91 \\
\hline SBER & 2.2361 & 0.02 & 0.07 & 0.91 \\
\hline VTBR & 2.4495 & 0.01 & 0.09 & 0.90 \\
\hline $\operatorname{MOEX} \alpha+$ & $\beta=2,213$ & $(1)^{0.02}$ & 0.03 & 0.95 \\
\hline AFKS & 2.6186 & 0.07 & 0.21 & 0.72 \\
\hline CBOM & 0.8660 & 0.16 & 0.28 & 0.56 \\
\hline GMKN & 1.5811 & 0.02 & 0.04 & 0.94 \\
\hline MAGN & 2.3452 & 0.02 & 0.07 & 0.91 \\
\hline CHMF & 2.0000 & 0.03 & 0.04 & 0.93 \\
\hline ALRS & - & - & 0.16 & 0.88 \\
\hline NLMK & 2.0702 & 0.07 & 0.05 & 0.88 \\
\hline MGNT & 2.1026 & 0.19 & 0.14 & 0.67 \\
\hline LNTA & 2.1794 & 0.04 & 0.11 & 0.85 \\
\hline AGRO & 4.1433 & 0.06 & 0.35 & 0.59 \\
\hline MVID & 2.4900 & 0.05 & 0.06 & 0.89 \\
\hline GCHE & 2.6458 & 0.02 & 0.14 & 0.84 \\
\hline MTSS & 1.8708 & 0.02 & 0.04 & 0.94 \\
\hline MFON & 1.9365 & 0.04 & 0.09 & 0.87 \\
\hline RTKM & 2.0000 & 0.01 & 0.08 & 0.91 \\
\hline MGTSP & 4.6771 & 0.08 & 0.45 & 0.47 \\
\hline TTLK & $\beta=\gamma^{-}$ & (1) - & 1) 1.00 & 0.42 \\
\hline
\end{tabular}
assets in Russian Stock exchange are demonstrated in Table 1.

TABLE I. CALCULATING RESULTS OF STOCK’S CONDITIONAL VOLATILITY

Next, let us calculate the coefficients of assets unilateral sensitivity to market changes. Fig. 2 demonstrates $\beta^{+}$daily values for Rosneft stock from 2014 to 2017.

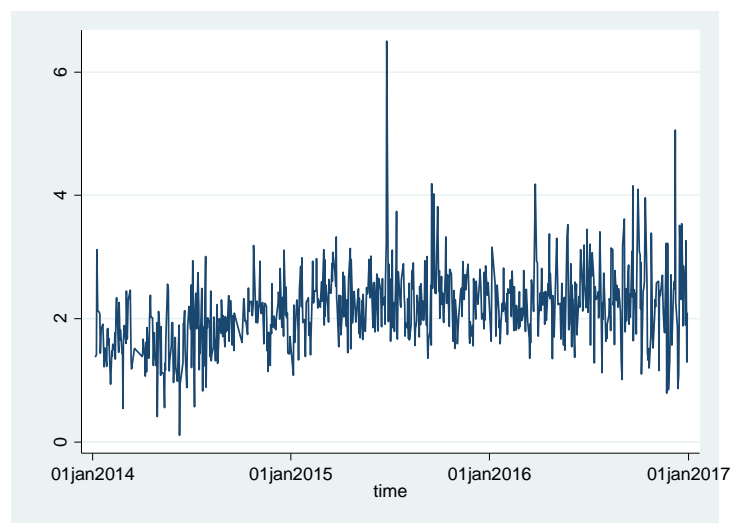

Fig. 2. $\beta^{+}$daily values for Rosneft stock from 2014 to 2017 .

Coefficients of assets unilateral sensitivity to market changes characteristics $\left(\beta_{1}^{+}, \beta_{2}^{-}\right)$are demonstrated in Table 2. 
TABLE II. COEFFICIENTS OF ASSETS UNILATERAL SENSITIVITY TO MARKET CHANGES CHARACTERISTICS $\left(\beta_{1}^{+}, \beta_{2}^{-}\right)$

\begin{tabular}{|l|c|c|c|c|c|c|}
\hline \multicolumn{1}{|c|}{ Assets } & $\overline{\sigma_{t}^{2}}$ & $\sigma_{\sigma_{t}^{2}}$ & $\overline{\beta^{+}}$ & $\sigma_{\beta^{+}}$ & $\overline{\beta^{-}}$ & $\sigma_{\beta^{-}}$ \\
\hline ROSN & 0.0004 & 0.0006 & 1.07 & 0.49 & 1.07 & 0.53 \\
\hline GAZP & 0.0003 & 0.0007 & 1.11 & 0.36 & 1.13 & 0.41 \\
\hline LKOH & 0.0004 & 0.0007 & 1.14 & 0.41 & 1.19 & 0.41 \\
\hline NVTK & 0.0005 & 0.0011 & 1.25 & 0.57 & 1.23 & 0.62 \\
\hline TRNFP & 0.0007 & 0.0015 & 0.99 & 0.92 & 0.99 & 0.84 \\
\hline SBER & 0.0004 & 0.0009 & 1.28 & 0.47 & 1.25 & 0.42 \\
\hline VTBR & 0.0005 & 0.0010 & 0.98 & 0.67 & 0.95 & 0.55 \\
\hline MOEX & 0.0005 & 0.0008 & 0.63 & 0.73 & 0.64 & 0.66 \\
\hline AFKS & 0.0017 & 0.0106 & 0.82 & 1.10 & 0.78 & 1.22 \\
\hline GMKN & 0.0004 & 0.0007 & 0.86 & 0.53 & 0.82 & 0.50 \\
\hline MAGN & 0.0007 & 0.0014 & 0.62 & 0.81 & 0.53 & 0.78 \\
\hline CHMF & 0.0005 & 0.0008 & 0.85 & 0.68 & 0.81 & 0.68 \\
\hline ALRS & 0.0007 & 0.0014 & 0.57 & 0.82 & 0.60 & 0.74 \\
\hline NLMK & 0.0005 & 0.0008 & 0.78 & 0.71 & 0.87 & 0.63 \\
\hline MGNT & 0.0005 & 0.0009 & 0.97 & 0.67 & 1.03 & 0.65 \\
\hline MTSS & 0.0005 & 0.0014 & 0.86 & 0.77 & 0.87 & 0.68 \\
\hline MFON & 0.0008 & 0.0015 & 0.46 & 0.79 & 0.53 & 0.86 \\
\hline RTKM & 0.0005 & 0.0012 & 0.70 & 0.61 & 0.69 & 0.66 \\
\hline
\end{tabular}

The results in Table 2 demonstrates that there is an asymmetry in the dynamics of coefficients of assets unilateral sensitivity to market changes.

TABLE III. PARAMETERS OF NEW VARIABLES $\left(a_{1 t}\right.$ AND $\left.a_{2 t}\right)$

\begin{tabular}{|l|c|c|c|c|c|c|}
\hline Assets & $\overline{a_{1}}$ & $\sigma_{a_{1}}$ & $\begin{array}{c}\mathrm{N} \\
\beta^{+}> \\
\left.\beta^{-}\right)\end{array}$ & $\begin{array}{c}\mathrm{W} \\
\left(\beta^{+}>\right. \\
\left.\beta^{-}\right)\end{array}$ & $\begin{array}{c}\mathrm{N} \\
\left(a_{2}=\right. \\
1)\end{array}$ & $\begin{array}{c}\% \\
\left(a_{2}=\right. \\
1)\end{array}$ \\
\hline ROSN & 2.1 & 0.6 & 367 & 50 & 123 & 17 \\
\hline GAZP & 2.2 & 0.5 & 341 & 47 & 120 & 16 \\
\hline LKOH & 2.3 & 0.5 & 363 & 49 & 134 & 18 \\
\hline NVTK & 2.5 & 0.8 & 379 & 52 & 144 & 20 \\
\hline TRNFP & 2.0 & 1.1 & 355 & 48 & 133 & 18 \\
\hline SBER & 2.5 & 0.6 & 370 & 50 & 156 & 21 \\
\hline VTBR & 1.9 & 0.8 & 379 & 51 & 125 & 17 \\
\hline MOEX & 1.3 & 0.8 & 375 & 51 & 123 & 17 \\
\hline AFKS & 1.6 & 1.5 & 387 & 52 & 107 & 14 \\
\hline GMKN & 1.7 & 0.6 & 383 & 52 & 130 & 18 \\
\hline MAGN & 1.2 & 1.0 & 380 & 51 & 108 & 15 \\
\hline CHMF & 1.7 & 0.8 & 378 & 51 & 141 & 19 \\
\hline ALRS & 1.2 & 0.9 & 355 & 48 & 130 & 17 \\
\hline NLMK & 1.6 & 0.8 & 328 & 44 & 102 & 14 \\
\hline MGNT & 2.0 & 0.8 & 351 & 47 & 103 & 14 \\
\hline MTSS & 1.7 & 0.9 & 388 & 52 & 137 & 18 \\
\hline MFON & 1.0 & 1.1 & 339 & 45 & 94 & 13 \\
\hline RTKM & 1.4 & 0.8 & 376 & 50 & 127 & 17 \\
\hline & & & & & & \\
\hline
\end{tabular}

Table 3 contains parameters of new variables $\left(a_{1 t}\right.$ and $\left.a_{2 t}\right)$ that are designed to test the first and third hypotheses.

TABLE IV. ECONOMETRIC ANALYSYS RESULTS CHECKING SIGNIFICANCE OF VARIABLES $a_{1 t}$ AND $a_{2 t}$

\begin{tabular}{rrrc}
\hline ROSN & $\sigma_{t}^{2}\left(\sigma_{t-1}^{2}\right)$ & $\sigma_{t}^{2}\left(\sigma_{t-1}^{2}, a_{1}\right)$ & $\sigma_{t}^{2}\left(\sigma_{t-1}^{2}, a_{1}, a_{2}\right)$ \\
\hline sd2RO & 0.00037 & 0.000074 & 0.000065 \\
& $(6.12)^{* *}$ & $(0.79)$ & $(0.70)$ \\
ARMA & 0.521 & 0.524 & 0.527 \\
& $(23.59)^{* *}$ & $(20.45)^{* *}$ & $(19.77)^{* *}$
\end{tabular}

a1RO

0.00014

0.00013

$(6.04)^{* *}$

$(4.82)^{* *}$

a2RO

0.00011

sigma

0.00046

$(239.88)^{*}$

0.00046

0.00045

$N$

732

$(243.75)^{* *}$

$(232.65)^{* *}$

732

The results in Table 4 demonstrate that the dynamics of coefficients of assets unilateral sensitivity to market changes and its asymmetry are significant factors in the context of interpretation of stocks return volatility based on the volatility clustering phenomenon.

\section{CONCLUSIONS}

Dynamics of coefficients of assets unilateral sensitivity to market changes (show a market's assessment interval) is a significant factor in the context of interpretation of stocks return volatility based on the volatility clustering phenomenon.

There is an asymmetry in the dynamics of coefficients of assets unilateral sensitivity to market changes.

Asymmetry in the dynamics of coefficients of assets unilateral sensitivity to market changes is a significant factor in the context of interpretation of stocks return volatility based on the volatility clustering phenomenon.

The equality of coefficients of assets unilateral sensitivity to positive and negative market changes is a necessary condition for the absence of arbitrage opportunities in the financial market.

The authors develop the definition of clustering stocks return volatility by describing relations among this phenomenon, Efficient Market Hypotheses and the existing models of pricing financial assets. The relative inability of the market to ensure full and coordinated implementation of accumulated information in asset price is a precondition for the emergence of clustering stocks return volatility at the micro-level. Directions for improvement of financial assets volatility assessment are demonstrated and approaches of arbitrage strategies formation for market information efficiency increasing are suggested using interpretation based on the volatility clustering phenomenon.

\section{RECCOMMENDATIONS AND FUTURE RESEARCH AREA}

Using the equality of coefficients of assets unilateral sensitivity to positive and negative market changes as a necessary condition for the absence of arbitrage opportunities in the financial market, financial institutes and regulators can offer new financial instruments and rules for increasing market efficiency. In addition, it will be interesting to use this arbitrage technique to search for collusion's elements in the financial market. In any case, new offered variables help to get new interpretation for describing stocks return volatility clustering (micro-level) and volatility forecasting. In future, 
the authors will try to describe the transformation mechanism between micro-level volatility clustering and macro-level volatility clustering using calculation methodology of the Diversification Potential concept and Diversification Potential Index, which will be especially important for forming Central Banks policy in the world.

\section{References}

[1] B. Mandelbrot, "The variation of certain speculative prices," Journal of Business, vol. 36, pp. 394-19, 1963.

[2] R. Engle, "Autoregressive conditional heteroscedasticity with estimates of variance of united kingdom inflation," Econometrica, vol. 50, 1982, pp. $987-1008$.

[3] M. Kendall, "The Analysis of Economic Time Series - Part 1: Prices," Journal of the Royal Statistical Society. Series A (General), vol. 116(1), pp. 11-25, 1953 .

[4] H. Markowitz, "Foundations of Portfolio Theory," Journal of Finance, vol. 46(2), pp. 469-477, 1991

[5] B. Mandelbrot, "Long-run linearity, locally Gaussian process, H-spectra and infinite variances," International Economic Review, vol. 10, pp. 81$111,1969$.

[6] E. Fama, "Efiicient Capital Markets: II," The Journal of Finance, vol. 46, 18. No. 5., pp. 1575-1617, 1991

[7] E. Andreou, N. Pittis and A. Spanos, "On Modelling Speculative Prices," The empirical Literature. Journal of Economic Surveys, vol 15(2), 187-220, 2001

[8] L. Bachelier, "Theorie de la Speculation," (English Translation; Cootner (ed.), 1964. Random Character of Stock Market Prices, MIT, 17-78)

[9] K. Pearson, "The problem of the Random Walk," Nature, vol 72, pp. 294-324, 1905 .

[10] S. Alexander, "Price Movements in Speculative Markets: Trends or Random Walks," Industrial Management Review, vol. 2(2), pp. 7-26, 1961

[11] R. Engle, T. Bollerslev, "Modelling the persistence of conditional variances," Econometric Reviews, vol. 5, no. 1, pp. 1-50, 1986.
[12] T. Bollerslev, "Generalized autoregressive conditional heteroskedasticity," Journal of Econometrics, vol. 31, no. 3, pp. 307327, 1986.

[13] T. Bollerslev, R. Chou and K. Kroner, "Arch modeling in finance: A review of the theory and empirical evidence," Journal of Econometrics, vol. 52, no. 1-2, pp. 5-59, 1992.

[14] Ch. Chang, L. Serrano and J. Jiménez-Martin, "Currency Hedging Strategies Using Dynamic Multivariate GARCH," SSRN Working Paper Series, 2012.

[15] E. Rubinshtein, A. Srivastava, "Optimal linear projections for enhancing desired data statistics," Statistics and Computing, vol. 20 (3), pp.267$282,2010$.

[16] D. Nelson, "Conditional heteroskedasticity in asset returns: A new approach," Econometrica, vol. 59, pp. 347-370, 1991.

[17] L. Glosten, R. Jagannathan and D. Runkle, "On the relation between the expected value and volatility of the nominal excess return on stocks," Journal of Finance, vol. 46, pp. 1779-1801, 1992.

[18] K. Morimune, "Volatility models," The Japanese Economic Review, vol. 58, no. 1, pp. 1-23, 2007.

[19] F. Bandi, J. Russel, "Separating microstructure noise from volatility," Journal of Financial Economics, 3, pp. 655-692, 2006.

[20] T.Andersen, T. Bollerslev, F. Diebold and P. Labys, "Exchange rate returns standardized by realized volatility are (nearly) Gaussian," Multinational Finance Journal, 4, pp. 159-179, 1999.

[21] L. Wang, A. Nagapetyan, E. Lutsenko and V. Pakhmutov, "Theory and methodology for financial infrastructure of foreign direct investment in developing countries: The BRICS case," International Review of Management and Marketing, vol 6(S1), pp. 179-183, 2016.

[22] F. Corsi, "A simple long memory model of realized volatility," Working paper, University of Southern Switzerland, 2004

[23] L. Liu, A. Patton and K. Sheppard, "Does anything beat 5 minute RV? A comparison of realized measures across multiple asset classes," Department of Economics Discussion Paper series, 645. University of Oxford, 2012

[24] A. Nagapetyan, E. Rubinshtein," Comparison of positive and negative risk indices as a tool for portfolio management," Actual Problems of Economics, vol 7, pp. 142-150, 2016. 